\title{
The influence of personality traits on emotion expression in bulimic spectrum disorders: A
} pilot study

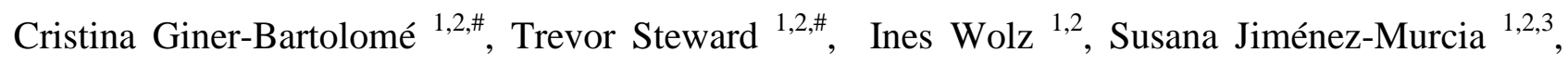
Roser Granero ${ }^{2,4}$, Salomé Tárrega ${ }^{4}$, José Antonio Fernández-Formoso ${ }^{5}$, Carles Soriano-Mas ${ }^{1,4,6}$, José M. Menchón ${ }^{1,3,6}$, Fernando Fernández-Aranda ${ }^{1,2,3, *}$

${ }^{1}$ Department of Psychiatry, Bellvitge University Hospital-IDIBELL, Barcelona, Spain.

2 CIBER Fisiopatología Obesidad y Nutrición (CIBERObn), Instituto de Salud Carlos III, Barcelona, Spain.

${ }^{3}$ Clinical Sciences Department, School of Medicine, University of Barcelona, Spain.

${ }^{4}$ Department of Psychobiology and Methodology, Autonomous University of Barcelona, Barcelona, Spain.

${ }^{5}$ CIBER, Instituto de Salud Carlos III, Madrid, Spain.

${ }^{6}$ CIBER Salud Mental (CIBERSAM), Instituto de Salud Carlos III, Barcelona, Spain.

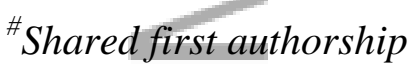

\section{*Correspondence:}

Fernando Fernández-Aranda, Ph.D., FAED

Department of Psychiatry and CIBEROBN, University Hospital of Bellvitge-IDIBELL c/ Feixa Llarga s/n,

08907-Barcelona, Spain

Tel.: +349326072 27. Fax.: +34932607193

ffernandez@bellvitgehospital.cat

This is the author manuscript accepted for publication and has undergone full peer review but has not been through the copyediting, typesetting, pagination and proofreading process, which may lead to differences between this version and the Version of Record. Please cite this article as doi: 10.1002/erv.2446

This article is protected by copyright. All rights reserved. 
Total words: 3.909

\section{Figures: 1}

Tables: 4

Supporting information (Tables): 1

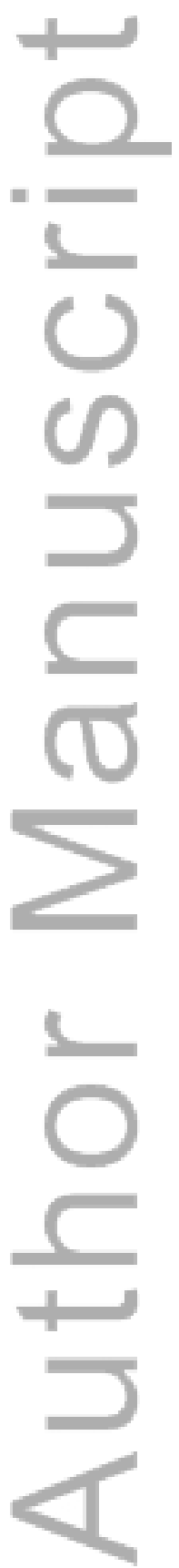

This article is protected by copyright. All rights reserved. 


\begin{abstract}
Facial expressions are critical in forming social bonds and in signaling one's emotional state to others. In eating disorder patients, impairments in facial emotion recognition have been associated with eating psychopathology severity. Little research however has been carried out on how bulimic spectrum disorder (BSD) patients spontaneously express emotions. Our aim was to investigate emotion expression in BSD patients and to explore the influence of personality traits. Our study comprised 28 BSD women and 15 healthy controls. Facial expressions were recorded while participants played a serious video game. Expressions of anger and joy were used as outcome measures. Overall, BSD participants displayed less facial expressiveness than controls. Among BSD women, expressions of joy were positively associated with reward dependence, novelty seeking and self-directedness, whereas expressions of anger were associated with lower selfdirectedness. Our findings suggest that specific personality traits are associated with altered emotion facial expression in patients with BSD.
\end{abstract}

Keywords: eating disorders; bulimic spectrum disorders; personality; emotion expression; serious video games.

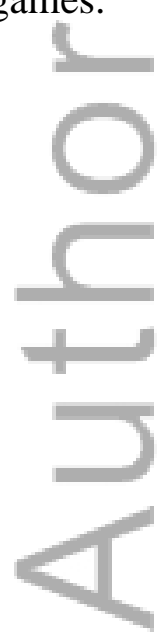

This article is protected by copyright. All rights reserved. 


\section{Introduction}

Eating disorders (ED) are marked by acute difficulties in socio-emotional processing, which are reflected, inter alia, in difficulties attending to positive facial expressions, reduced eye contact when interacting with others and a tendency to avoid expressing emotions (Dapelo et al., 2015; Treasure,

Corfield, \& Cardi, 2012). Recent studies focusing on facial emotion expression using computer tasks have also described diminished emotion expression (Dapelo, Bodas, Morris \& Tchanturia, 2016; Davies, Schmidt, Stahl, \& Tchanturia, 2011; Tárrega et al., 2014) and attentional bias to negative social affective stimuli (Harrison, Sullivan, Tchanturia, \& Treasure, 2010) in ED patients compared to healthy controls (HC). These impairments are believed to play a pivotal role as a maintenance factor of disturbed eating behavior (Treasure et al., 2012) and seem to be underpinned by overlapping alterations in brain circuits processing reward and social cognition (Via et al., 2015). Neuroimaging studies have also revealed altered neural responses to facial stimuli in patients with both bulimia nervosa (BN) (Ashworth et al., 2011) and anorexia nervosa (AN) (Fonville, Giampietro, Surguladze, Williams, \& Tchanturia, 2014).

Apart from being common in ED, reduced emotion expression has also been associated with autistic spectrum disorders (McIntosh, Reichmann-Decker, Winkielman, \& Wilbarger, 2006; Stel, Van Den Heuvel, \& Smeets, 2008), neurological disorders such as Parkinson's disease (Clark, Neargarder, \& Cronin-Golomb, 2010) and other mental disorders (namely psychotic, obsessive, affective and personality disorders) (Davies et al., 2016; Bersani et al., 2012; Renneberg, Heyn, Gebhard, \& Bachmann, 2005).

Facial expressions are crucial signals for social communication because they provide information about the mood and emotions that individuals are experiencing at a given moment. Therefore, facial 
Personality traits and emotion expression expressiveness is an essential factor in promoting effective communication and fostering relationships with others. In fact, it is known that facial expressions have an adaptive function and their importance in social interactions and social intelligence is extensibility recognized (Schmidt \& Cohn, 2001). For this reason, impairments in emotion expression are understood to contribute to poor social functioning and worsening clinical characteristics, and have become an important target in the treatment of ED patients (Lang et al., 2016).

Facial emotion expression can be understood as a behavioral facet of emotion regulation, whereby differences in personality traits manifest in specific facial expressions of emotions such as joy or anger (Tchanturia, Dapelo, Harrison, \& Hambrook, 2015). In the case of ED patients, emotion regulation difficulties have been associated with greater ED severity (Danner, Evers, Stok, Van Elburg, \& De Ridder, 2012), ED subtype (Wolz et al., 2015), more general psychopathology (Werner \& Gross, 2010), and poor prognosis (Wallace, Masson, Safer, \& von Ranson, 2014). It is important to note that difficulties in emotion regulation could depend on ED subtype (Danner, Sternheim, \& Evers, 2014; Wolz et al., 2015). In this sense, it has been found that BN and binge eating disorder (BED) patients share similar emotional impairments, and that patients with $\mathrm{BN}$ or an Other Specified Eating or Feeding Disorder (OSFED) tend to show greater difficulties in emotion regulation than those with AN (Danner et al., 2014; Wolz et al., 2015). In both BN and BED, greater symptom severity is linked to less frequent use of adaptative emotion regulation strategies (such as cognitive reappraisal) and a greater tendency to regulate emotions using disadvantageous methods (mainly by suppressing negative emotions) (Danner et al., 2014). Furthermore, other studies on emotion regulation have found similar results regarding impulsivity in BN and BED (Brockmeyer et al., 2014; Svaldi, Griepenstroh, Tuschen-Caffier, \& Ehring, 2012). Moreover, negative mood appears to be mediated by pathological behaviors in both disorders, such as binging 
and vomiting. Thus, impulsive eating behaviors can act as an attempt to cope with aversive affect by providing short-term relief in either disease (Brockmeyer et al., 2014).

Given the presence of emotion regulation problems in these disorders, it could be hypothesized that patients with $\mathrm{BN}$ or a bulimic spectrum disorder (BSD) might show impairments in facial emotion expression, though there is a paucity of studies in the literature on the subject.

To our knowledge, even though there do exist some studies that have identified an association between facial emotion perception/recognition and personality traits (Andric et al., 2015; Mardaga \& Iakimova, 2014), no studies to date have explored associations between these factors in BSD patients. It has been found that personality traits such as novelty seeking, harm avoidance, reward dependence and self-directedness play an important function in the development, maintenance and prognosis of BSDs (Atiye, Miettunen, \& Raevuori-Helkamaa, 2015; Fassino, Amianto, Gramaglia, Facchini, \& Abbate Daga, 2004). Other studies have suggested that facial expressiveness impairments in BSD patients that could contribute to problems in social functioning. For example, BN patients tend to show less facial expressions of anger even though they report feeling angry (Claes et al., 2012; Tárrega et al., 2014). This incongruence between their true feelings and their facial expressions suggests a tendency to suppress negative emotions. However, further research on the relationship between personality traits and emotion facial expressions are needed before such a conclusion can be reached.

As such, the primary objectives of the present study were threefold: 1) to compare facial emotion expression between BSD patients and $\mathrm{HC} ; 2$ ) to analyze the association between emotion expression (specifically joy and anger) and personality traits, after controlling for ED severity, depressive symptomatology and body mass index (BMI); 3) To find a model to predict facial 

emotion expression in BSD patients including personality traits, while controlling for ED severity, depressive symptomatology and BMI. Understanding this interaction has clinical implications as spontaneous facial expressions serve as a vital tool for showing empathy, establishing beneficial social bonds and in turn, improving treatment outcome (Arcelus, Haslam, Farrow, \& Meyer, 2013; Hartmann, Zeeck, \& Barrett, 2010).

Given the aforementioned evidence for impaired emotion expression in $\mathrm{BN}$ and the established links between BSD and specific personality traits (mainly novelty seeking, harm avoidance, reward dependence and self-directedness), we hypothesize that: 1) BSD patients will exhibit diminished facial emotion expression and more disparate personality traits compared to HC; 2) levels of facial emotion expression will be associated with specific personality traits (higher anger expression with novelty seeking; higher joy expression with reward dependence and lower joy expression with harm avoidance) in BSD patients, and 3) our model will be able to predict facial emotion expression levels via specific personality traits.

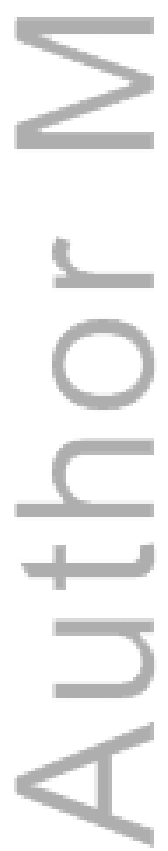

This article is protected by copyright. All rights reserved. 


\section{Materials and Methods}

\section{Participants}

A total of 43 participants were included in this study: 28 patients with BSD, namely $\mathrm{BN}(n=23)$, OSFED-purging subtype $(n=1)$ and $\operatorname{BED}(n=4)$, and 15 HC. Patients were diagnosed according to DSM-5 diagnostic criteria (American Psychiatric Association, 2013), by means of the Spanish version the SCID-I (First, Spitzer, Gibbon, \& Williams, 1997). All interviewers were conducted by experienced psychologists and psychiatrists. Patients were consecutive referrals for assessment and outpatient treatment at Bellvitge University Hospital (Barcelona, Spain). The HC group comprised volunteer participants from our hospital staff and student interns.

All participants were female. The average age for $\mathrm{HC}$ was $29.5(\mathrm{SD}=6.5)$ years old, and 30.9 $(\mathrm{SD}=10.0)$ for patients. The average duration of the BSD for patients was 9.98 years $(\mathrm{SD}=7.5)$ and the mean number of weekly binge episodes was $4.5(\mathrm{SD}=3.6)$.

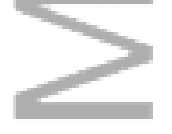

The inclusion criteria to participate in the study were being a female between the ages of 18 and 45 , and diagnosis of a BSD [BN, BED or OSFED (BN, BED or purging subtype)]. The exclusion criteria for both the patient group and the HC group were: a current or lifetime diagnosis of AN (or any other ED in the case of $\mathrm{HC}$ ), being male, suffering from a primary psychiatric or neurological disorder (e.g. psychotic disorder, bipolar disorder, major depressive disorder, substance abusedependence disorder, etc.), and having a current or lifetime diagnosis of behavioral technology addictions (internet or video game addiction). As participants were required to engage in different tasks during the recording of facial expressions, those with any psychiatric or neurological disorders 
that could interfere with the understanding of game instructions and/or performance (e.g. impairments in visual-spatial abilities, attentional problems, etc.) were excluded from the study.

The study was approved by the Ethics Committee of the Bellvitge University Hospital and written informed consent was obtained from all participants.

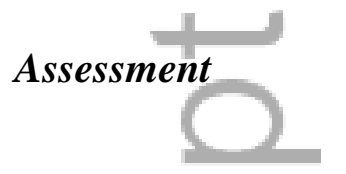

Psychometric measures

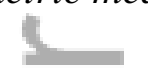

Temperament and Character Inventory-Revised (TCI-R) (Cloninger, 1999): This is a 240-item, reliable and valid questionnaire that measures seven dimensions of personality: four temperament dimensions (harm avoidance, novelty seeking, reward dependence and perseverance) and three character dimensions (self-directedness, cooperativeness and self-transcendence). Performance of the Spanish version of the original questionnaire (Gutierrez et al., 2001) and the revised version (Gutiérrez-Zotes et al., 2004) has been documented. The scales in the latter showed an internal consistency (coefficient alpha) of 0.87 . In the current study, this instrument was used as a measure of personality traits.

Eating Disorder Inventory 2 (EDI-2) (Garner, 1991): This is a reliable and valid 91-item multidimensional self-report questionnaire that assesses different cognitive and behavioral characteristics, which are typical in ED. When this instrument was validated in a Spanish population, a mean internal consistency of 0.63 (coefficient alpha) was found (Garner, 1998). In the current study, the total score was used as a measure of ED severity. 
Personality traits and emotion expression Symptom Check List-90 items-Revised (SCL-90-R) (Derogatis, 1990): This is a 90-item multidimensional self-report assessment measure for a broad range of psychological problems/symptoms. This scale has been validated in a Spanish population (Derogatis, 2002), obtaining a mean internal consistency of 0.75 (Coefficient alpha). In the current study, the depression dimension was used as a control variable as depression has been shown to influence facial expression (Trémeau et al., 2005).

\section{Emotion expression measure}

Facial recognition software: As described in previous studies (Claes et al., 2012; Fernandez-Aranda et al., 2012; Jimenez-Murcia et al., 2009), this facial affect recognition software was designed and developed for a serious game platform named "Playmancer". Serious games are games designed for a specific purpose beyond pure entertainment (Gaudet-Blavignac \& Geissbuhler, 2012). They can be applied with an explicit goal in contexts such as defense, education and healthcare. In healthcare, these games are used for educational, preventive and/or therapeutic purposes (Gaudet-Blavignac \& Geissbuhler, 2012). Playmancer is usually used as an additional therapeutic tool, combined with standard psychological ED treatment (Fernandez-Aranda et al., 2012; Jimenez-Murcia et al., 2009). The main goal of this intervention is to improve self-control, to reduce impulsivity and to learn how to regulate emotions (such as frustration and anxiety) when the player is confronted with several challenges through different activities (mini-games). The video game consists of three mini-games: (1) The Face of Cronos: The player has to climb up a cliff in which obstacles appear depending on the player's arousal level (based on biofeedback); (2) Treasures of the Sea: A swimming game in which the player has to collect different objects and fish while conserving their oxygen supply. High arousal makes the task more difficult; (3) Sign of the Magupta: A relaxation game in which 
the player connects a constellation of stars through breathing control. Slow deep breathing allows the connections between stars to form. Facial expression levels were measured while subjects played the video game. Specific facial expressions were detected by an integrated camera and processed by the facial tracking component. For this study, we used anger and joy emotions as outcome measures (Figure 1). For a more detailed description of previously conducted experiments to calibrate the facial recognition software, see Claes et al., 2012. The measure provided by this tool is the total amount of time (in seconds) that subjects express a particular emotion throughout the duration of the first video game session. Facial expression levels have previously been tested in AN as well as in BN groups using this instrument (Claes et al., 2012; Tárrega et al., 2014).

--- Insert Figure 1 ---

\section{Procedure}

Before starting the video game intervention, both groups completed the self-report questionnaires (TCI-R, EDI-2 and SCL-90-R) that form part of the assessment and diagnostic protocol that is followed in our established treatment program. Participants from the HC group were recruited from the local hospital/university community and were invited to take part in one session of the video game intervention. In the case of the BSD group, video game sessions took place on the same days patients were present for their standard treatment (i.e. Cognitive Behavioral Therapy -CBT-). Emotion expression data from all participants were obtained from the facial recognition software and only data from the first video game session were used in our analysis.

\section{Statistical analysis}

Statistical analysis was carried out with Stata13.1 for Windows. First, means on the EDI-2, SCL90-R, TCI-R questionnaires and BMI were compared between BSD patients and HC using t-test 
procedures. The comparison of mean scores for the facial expression of the emotions joy and anger were compared between BSD and HC with Poisson Regression (a method used to model count data, which assumes that the dependent variable has a Poisson distribution and the logarithm of its expected values can be modeled by a linear combination of the parameters). Effect size for the mean comparisons was estimated through the Cohen's- $d$ coefficient $(|d|>0.50$ was considered moderate effect size and $|d|>0.80$ was considered high effect size).

Second," partial correlations (adjusted for BMI and SCL-90-R depression scores) estimated the association between the personality traits measured through the TCI-R and emotion expression duration for the BSD sample ( $n=28)$. $|r| \geq 0.30$ was considered good effect size.

Finally, linear regression in two step/blocks assessed the incremental predictive capacity of the personality traits on the criteria emotion expression measures. These models were stratified (separately) for the BSD and HC group. For the BSD group: a) the first step/block included and set the covariates: BMI, ED severity (EDI-2 total score) and depression level (SCL-90R depressive score); b) the second step/block automatically selected the significant TCI-R scale predictors through a step-wise procedure. The same procedure was conducted to obtain the predictive model of emotion expression scores in the HC group, but for this group the first step only included BMI and the SCL-90-R depressive scores as covariates. The predictive capacity of each block was measured through the increase in $R^{2}$ coefficient $\left(\Delta R^{2}\right)$.

Due to the multiple statistical comparisons, Type-I error inflation was controlled through Bonferroni-Finner correction. 


\section{Results}

\section{Comparison of clinical measures between BSD patients and $\mathrm{HC}$}

Table 1 includes the distribution of the EDI-2, SCL-90-R, TCI-R raw scores and BMI in each group (BSD and $\mathrm{HC}$ ), and the results of the mean comparisons obtained through t-test procedures. BSD patients obtained statistically higher BMI, as well as higher scores on all the scales for the EDI-2 and the SCL-90-R compared to HC group. Effect sizes for the mean differences (measured with the Cohen's- $d$ coefficient) were in the high range (only the EDI-2 perfectionism scale achieved a mean difference with a moderate effect size, $d=0.67$ ).

For the personality traits measured with the TCI-R, the BSD group scored significantly higher on the harm avoidance scale compared to $\mathrm{HC}$, while reward dependence and self-directedness scores were significantly lower for BSD patients.

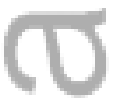

--- Insert Table 1 ---

\section{Comparison of facial expression between BSD patients and $\mathrm{HC}$}

Table 2 includes the mean comparison for the facial expression of joy and anger between BSD and $\mathrm{HC}$ groups. HC patients expressed more joy compared to BSD, but effect size for mean difference was poor $(d=0.18)$. Facial anger expression was lower for BSD patients, and effect size for mean difference was in the moderate range $(d=0.50)$.

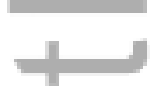

--- Insert Table 2 ---

\section{Association between personality traits and facial expression in BSD patients}

Table 3 includes the partial correlations (adjusted for BMI, EDI-2 total and SCL-90-R depression scores) between the personality traits (TCI-R scores) and the expression levels of joy and anger in 
the BSD group. Facial expressions of joy positively correlated with scores in novelty seeking, reward dependence and self-directedness (the higher the personality trait, the higher the joy expression score). Expression levels of anger negatively correlated with self-directedness.

--- Insert Table 3 ---

\section{Predictive capacity of personality traits on facial expression}

The first multiple regression in Table 4 corresponds to the predictive model for the outcome of joy expression for the BSD group. After adjusting for the covariates BMI, ED severity (EDI-2 total score) and depressive symptomatology (SCL-90R depression score), TCI-R reward dependence and self-directedness scores were retained in the model since they obtained significant predictive capacity: higher scores in these personality traits predicted higher joy expression levels. The specific incremental validity of the reward dependence and self-directedness score on the facial joy measure was $\mathrm{R}^{2}=.304(p=.018)$.

The second multiple regression in Table 4 includes the parameters of the predictive model for the

outcome of anger expression. After adjusting for the same covariates as the previous model, the TCI-R self-directedness score was entered and retained. A significant negative association was obtained between this predictor and the criterion: lower scores in this self-directedness predicted higher levels of anger expression. The specific incremental validity of the self-directedness score on the facial anger level was $\mathrm{R}^{2}=.221(p=.026)$

--- Insert Table 4 ---

Table S1 (Supporting Information) includes the predictive models for the HC sample. After adjusting by the covariates BMI and SCL-90R depression level, the reward dependence score was 
Personality traits and emotion expression retained in the second block of the regression models and their predictive capacity was only quasisignificant ( $p=.077$ for the expression of joy and $p=.064$ for anger).

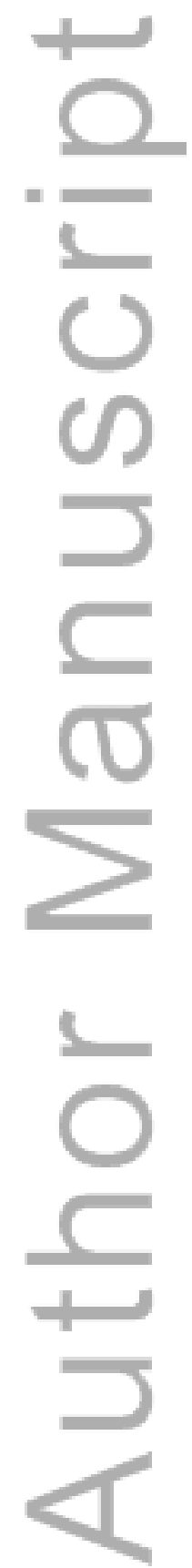

This article is protected by copyright. All rights reserved. 


\section{Discussion}

The aim of the present study was to explore the association between facial emotion expression and personality traits in patients with BSD compared to $\mathrm{HC}$. We also sought to develop a model to predict emotion facial expression in BSD patients, including personality traits. Our initial hypotheses were supported in that BSD patients showed diminished facial expression compared to HC and more altered personality traits. BSD patients scored significantly higher for harm avoidance than the HC group and also had significantly lower reward dependence and self-directedness.

As expected, we found significant positive associations between facial expressions of joy and reward dependence. Contrary to our hypothesis, we did not find any significant associations with harm avoidance. In contrast, facial expressions of joy positively correlated with novelty seeking. This association between heightened emotion expression and novelty seeking is of clinical relevance as other research has found that high novelty seeking is common in BN patients with impulse control disorders (Fernández-Aranda et al., 2006), and that these traits can favor the maintenance of binge eating syndromes (Castellini et al., 2012) or be predictive of treatment dropout (Agras et al., 2000).

Interestingly, higher self-directedness was positively correlated with expressions of joy and negatively correlated with expressions of anger. Our step regression model also associated higher anger expression with poorer self-directedness and greater joy expression with higher selfdirectedness. Self-directedness is defined as the ability to regulate and adapt behavior to the demands of a situation in order to achieve a chosen goal (Cloninger, Svrakic, \& Przybeck, 1993) and people with low self-directedness are described as being reactive and as suffering from maladaptive emotion activation which leads them to act out rashly. Self-directedness is known to be 
a predictor of long-term outcomes in patients with BN (Rowe et al., 2011) and BN patients with a predisposition to anger have been found to have high rates of treatment dropout (Fassino, AbbateDaga, Piero, Leombruni, \& Rovera, 2003). People with low self-directedness are hypothesized to suffer from an all-or-nothing form of dichotomous reasoning which produces a sense of frustration (Cloninger, Przybeck, Svrakic, \& Wetzel, 1994). As such, this line of thinking could hinder the establishment and maintenance of a therapeutic relationship with BN patients. A crucial aspect of CBT treatment involves acceptance of responsibility for one's choices and promoting a positive attitude towards change (Dalle Grave et al., 2007; Fairburn, Marcus, \& Wilson, 1993) and patients with greater facial anger expression may be in particular need of approaches that also target the mature development of self-directed behavior. The use of facial reactivity to ascertain whether low self-directedness needs to be addressed could be helpful in planning targeted temperament-based treatments specifically for BSD patients (Kaye et al., 2015).

Our statistical model points to higher reward dependence being a predictor of greater facial expression of joy when controlling for clinically-relevant variables such as BMI, ED symptom severity and depressive symptomatology. The study adds to earlier studies which suggest that highly reward dependent individuals may use facial expressions of joy to look for social approval and avoid rejection, and are hence, more vulnerable to societal pressures (Ioannou \& Fox, 2009). Likewise, reward dependence has been found to be correlated to higher body dissatisfaction in ED patients (Segura-García, Chiodo, Sinopoli, \& De Fazio, 2013) and further reaffirms the importance of needing to please others, not only through the use of facial expression but also by one's physical appearance. Recovered BN patients have been found to decrease the level of discordance between their implicit and explicit emotions indicating that, after remission, BN patients are able to exhibit a more authentic emotional response (Tárrega et al., 2014). Novel approaches which address these 
concerns have thus far provided positive results though further studies in larger samples are need to fully confirm their effectiveness (Davies, Schmidt, \& Tchanturia, 2013; Tchanturia et al., 2015).

This study has several strengths, primarily its novel tracking of facial activity without the use of emotion-specific stimuli. Although facial reactivity has previously been studied in BN (Claes et al., 2012; Tárrega et al., 2014), this is, to the extent of our knowledge, the first time that the relationship between personality traits and spontaneous emotion expression has been explored in BSD patients. Information linking personality traits to facial expressiveness could potentially be used by clinicians to identify which patients have greater impairments in expressing emotion and hence are in greater need of interventions that address social functioning issues.

Nonetheless, this study has several limitations worth mentioning. First, the study's small sample size greatly limited its power and we strongly suggest readers err on the side of caution when interpreting our results. We must stress that we have conducted a pilot study and that larger and more diverse samples are needed before confirming the generalizability of these results. Future studies should explore the influence of personality and facial recognition in other ED groups. The other main limitation of the study is that our measure only included two emotions (joy and anger) and the possibility that BSD patients expressed additional emotions (sadness, boredom, etc.) must be considered.

In conclusion, our findings indicate that patients with a BSD have altered emotion expression compared to $\mathrm{HC}$ and that emotion expression levels are influenced by personality traits in these patients. Given the importance of facial expressiveness in interpersonal interactions and the maintaining role that social impairment has in patients with BSD, this study supports the notion that 
Personality traits and emotion expression facial expressiveness and effective communication strategies should be addressed in treatment interventions in order to improve social functioning and overall outcomes.

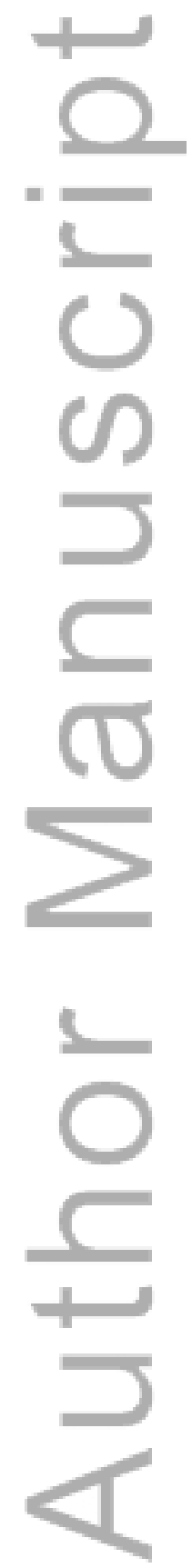

This article is protected by copyright. All rights reserved. 
Personality traits and emotion expression

\section{Acknowledgments}

This manuscript and research was supported by grants from Instituto de Salud Carlos III (ISCIII) (FIS PI14/00290) and co-funded by FEDER funds /European Regional Development Fund (ERDF), a way to build Europe. CIBER Fisiopatología de la Obesidad y Nutrición (CIBERobn) and CIBER Salud Mental (CIBERSAM), are both initiatives of ISCIII. We would like to thanks Playmancer consortium for their contribution in developing this Platform and Serious Video Game. CGB and IW were supported by a pre-doctoral grant (PFIS-FI12/00470 and AGAUR-2014FI_B 00372, respectively). TS is supported by grants from the Instituto de Salud Carlos III (FIS PI14/00290 and CIBERobn). CSM is funded by a 'Miguel Servet' contract from the Instituto de Salud Carlos III (CP10/00604). The funders had no role in the study design, data collection and analysis, decision to publish, or preparation of the manuscript.

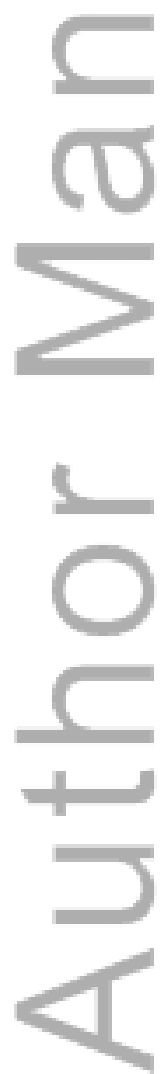

This article is protected by copyright. All rights reserved. 


\section{References}

Agras, W. S., Crow, S. J., Halmi, K. A., Mitchell, J. E., Wilson, G. T., \& Kraemer, H. C. (2000). Outcome predictors for the cognitive behavior treatment of bulimia nervosa: data from a multisite study. Am J Psychiatry, 157(8), 1302-1308.

American Psychiatric Association. (2013). Diagnostic and Statistical Manual of Mental Disorders. 5th Edition. DSM-5. Arlington, VA: American Psychiatric Publishing.

Andric, S., Maric, N. P., Knezevic, G., Mihaljevic, M., Mirjanic, T., Velthorst, E., \& van Os, J. (2015). Neuroticism and facial emotion recognition in healthy adults. Early Intervention in Psychiatry, http://doi.org/10.1111/eip.12212. In press

Arcelus, J., Haslam, M., Farrow, C., \& Meyer, C. (2013). The role of interpersonal functioning in the maintenance of eating psychopathology: a systematic review and testable model. Clin Psychol Rev, 33(1), 156-167.

Ashworth, F., Pringle, A., Norbury, R., Harmer, C. J., Cowen, P. J., \& Cooper, M. J. (2011). Neural response to angry and disgusted facial expressions in bulimia nervosa. Psychological Medicine, 41(11), 2375-2384. http://doi.org/10.1017/S0033291711000626

Atiye, M., Miettunen, J., \& Raevuori-Helkamaa, A. (2015). A Meta-Analysis of Temperament in Eating Disorders. European Eating Disorders Review, 23(2), 89-99. http://doi.org/10.1002/erv.2342

Bersani, G., Bersani, F. S., Valeriani, G., Robiony, M., Anastasia, A., Colletti, C., ... Saverio, F. (2012). Comparison of facial expression in patients with obsessive-compulsive disorder and schizophrenia using the Facial Action Coding System: a preliminary study. Neuropsychiatric Disease and Treatment, 8, 537-547. http://doi.org/10.2147/NDT.S37174

Brockmeyer, T., Skunde, M., Wu, M., Bresslein, E., Rudofsky, G., Herzog, W., \& Friederich, H. C. (2014). Difficulties in emotion regulation across the spectrum of eating disorders. Comprehensive Psychiatry, 55(3), 565-571. http://doi.org/10.1016/j.comppsych.2013.12.001

Castellini, G., Mannucci, E., Lo Sauro, C., Benni, L., Lazzeretti, L., Ravaldi, C., ... Ricca, V. (2012). Different moderators of cognitive-behavioral therapy on subjective and objective binge eating in bulimia nervosa and binge eating disorder: a three-year follow-up study. Psychotherapy and Psychosomatics, 81(1), 11-20. http://doi.org/10.1159/000329358 
Claes, L., Jimenez-Murcia, S., Santamaria, J. J., Moussa, M. B., Sanchez, I., Forcano, L., ... Fernandez-Aranda, F. (2012). The facial and subjective emotional reaction in response to a video game designed to train emotional regulation (Playmancer). Eur Eat Disord Rev, 20(6), 484-489.

Clark, U. S., Neargarder, S., \& Cronin-Golomb, A. (2010). Visual exploration of emotional facial expressions in Parkinson's disease. Neuropsychologia, 48(7), 1901-1913. http://doi.org/10.1016/j.neuropsychologia.2010.03.006

Cloninger, C. R. (1999). The Temperament and Character Inventory-Revised. St Louis, MO: Center for Psychobiology of Personality, Washington University.

Cloninger, C. R., Przybeck, T. R., Svrakic, D. M., \& Wetzel, R. D. (1994). The Temperament and Character Inventory (TCI): a guide to its development and use. St. Louis, Missouri: Center for Psychobiology of Personality.

Cloninger, C. R., Svrakic, D. M., \& Przybeck, T. R. (1993). A psychobiological model of temperament and character. Arch Gen Psychiatry, 50(12), 975-990.

Dalle Grave, R., Calugi, S., Brambilla, F., Abbate-Daga, G., Fassino, S., \& Marchesini, G. (2007). The effect of inpatient cognitive-behavioral therapy for eating disorders on temperament and character. Behav Res Ther, 45(6), 1335-1344.

Danner, U. N., Evers, C., Stok, F. M., Van Elburg, A. A., \& De Ridder, D. T. D. (2012). A double burden: Emotional eating and lack of cognitive reappraisal in eating disordered women. European Eating Disorders Review, 20(6), 490-495. http://doi.org/10.1002/erv.2184

Danner, U. N., Sternheim, L., \& Evers, C. (2014). The importance of distinguishing between the different eating disorders (sub)types when assessing emotion regulation strategies. Psychiatry Research,215(3), 727-732. http://doi.org/10.1016/j.psychres.2014.01.005

Dapelo M, Bodas S, Morris R, Tchanturia K. (2016) Deliberately generated and Imitated Facial Expressions of Emotions in people with Eating Disorders. Journal of Affective Disorders, 191, 1-7. http://doi.org/10.1016/j.jad.2015.10.044

Dapelo, M. M., Hart, S., Hale, C., Morris, R., Lynch, T. R., \& Tchanturia, K. (2015). Facial expression of positive emotions in individuals with eating disorders. Psychiatry Research, 230(1), 70-77. http://doi.org/10.1016/j.psychres.2015.08.019 
Davies, H., Schmidt, U., Stahl, D., \& Tchanturia, K. (2011). Evoked facial emotional expression and emotional experience in people with anorexia nervosa. International Journal of Eating Disorders, 44(6), 531-539. http://doi.org/10.1002/eat.20852

Davies, H., Schmidt, U., \& Tchanturia, K. (2013). Emotional facial expression in women recovered from anorexia nervosa. BMC Psychiatry, 13(1), 1-18. http://doi.org/10.1186/1471-244X-13291

Davies H, Wolz I, Leppanen, F Fernandez Aranda, U Schmidt, Tchanturia K. (2016) Facial expression to emotional stimuli in non-psychotic disorders: A systematic review and metaanalysis. Neuroscience \& Biobehavioral Reviews http://doi.org/10.1016/j.neubiorev.2016.02.015. In press

Derogatis, L. R. (1990). SCL-90-R. Administration, scoring and procedures manual. Baltimore, MD: Clinical Psychometric Research.

Derogatis, L. R. (2002). SCL-90-R. Cuestionario de 90 síntomas-Manual. Madrid: TEA Editorial.

Fairburn, C., Marcus, M., \& Wilson, G. (1993). Cognitive-behavioral therapy for binge eating and bulimia nervosa: a comprehensive treatment manual. In C. Fairburn \& G. Wilson (Eds.), Binge eating: nature,assessment and treatment. (pp. 361-404). New York: Guilford Press.

Fassino, S., Abbate-Daga, G., Piero, A., Leombruni, P., \& Rovera, G. G. (2003). Dropout from brief psychotherapy within a combination treatment in bulimia nervosa: role of personality and anger. Psychother Psychosom, 72(4), 203-210.

Fassino, S., Amianto, F., Gramaglia, C., Facchini, F., \& Abbate Daga, G. (2004). Temperament and character in eating disorders: Ten years of studies. Eating and Weight Disorders, 9(2), 81-90. http://doi.org/10.1007/BF03325050

Fernández-Aranda, F., Jiménez-Murcia, S., Alvarez-Moya, E. M., Granero, R., Vallejo, J., \& Bulik, C. M. (2006). Impulse control disorders in eating disorders: clinical and therapeutic implications. Comprehensive Psychiatry, 47(6), 482-488. http://doi.org/10.1016/j.comppsych.2006.03.002

Fernandez-Aranda, F., Jimenez-Murcia, S., Santamaria, J. J., Gunnard, K., Soto, A., Kalapanidas, E., ... Penelo, E. (2012). Video games as a complementary therapy tool in mental disorders: PlayMancer, a European multicentre study. J Ment Health, 21(4), 364-374. 
First, M. B., Spitzer, R. L., Gibbon, M., \& Williams, J. B. W. (1997). Structured Clinical Interview for DSM-IV Axis I disorders-Clinical Version (SCID-CV). Washington: American Psychiatric Press.

Fonville, L., Giampietro, V., Surguladze, S., Williams, S., \& Tchanturia, K. (2014). Increased BOLD signal in the fusiform gyrus during implicit emotion processing in anorexia nervosa. NeuroImage: Clinical, 4, 266-273. http://doi.org/10.1016/j.nicl.2013.12.002

Garner, D. M. (1991). Eating Disorder Inventory-2. Odessa: Psychological Assessment Resources.

Garner, D. M. (1998). Inventario de Trastornos de la Conducta Alimentaria (EDI-2)-Manual. Madrid: TEA.

Gaudet-Blavignac, C., \& Geissbuhler, A. (2012). Serious games in health care: a survey. Yearbook of Medical Informatics, 7, 30-33.

Gutierrez, F., Torrens, M., Boget, T., Martin-Santos, R., Sangorrin, J., Perez, G., \& Salamero, M. (2001). Psychometric properties of the Temperament and Character Inventory (TCI) questionnaire in a Spanish psychiatric population. Acta Psychiatr Scand, 103(2), 143-147.

Gutiérrez-Zotes, J. A., Bayón, C., Montserrat, C., Valero, J., Labad, A., Cloninger, R. C., \& Fernández-Aranda, F. (2004). Inventario del Temperamento y el Carácter-Revisado (TCI-R). Baremación y datos normativos en una muestra de población general. Actas Españolas de Psiquiatría, 32(1), 8-15.

Harrison, A., Sullivan, S., Tchanturia, K., \& Treasure, J. (2010). Emotional functioning in eating disorders: attentional bias, emotion recognition and emotion regulation. Psychological Medicine, 40(11), 1887-1897. http://doi.org/10.1017/S0033291710000036

Hartmann, A., Zeeck, A., \& Barrett, M. S. (2010). Interpersonal problems in eating disorders. International Journal of Eating Disorders, 43(7), 619-627. http://doi.org/10.1002/eat.20747

Ioannou, K., \& Fox, J. R. (2009). Perception of threat from emotions and its role in poor emotional expression within eating pathology. Clin Psychol Psychother, 16(4), 336-347.

Jimenez-Murcia, S., Fernandez-Aranda, F., Kalapanidas, E., Konstantas, D., Ganchev, T., Kocsis, O., ... Davarakis, C. (2009). Playmancer project: a serious videogame as an additional therapy tool for eating and impulse control disorders. Stud Health Technol Inform, 144, 163-166.

Kaye, W. H., Wierenga, C. E., Knatz, S., Liang, J., Boutelle, K., Hill, L., \& Eisler, I. (2015). Temperament-based Treatment for Anorexia Nervosa. European Eating Disorders Review: 
Personality traits and emotion expression

The Journal of the Eating Disorders Association, 23(1), 12-18. http://doi.org/10.1002/erv.2330

Lang, K., Larsson, E. E. C., Mavromara, L., Simic, M., Treasure, J., \& Tchanturia, K. (2016). Diminished facial emotion expression and associated clinical characteristics in Anorexia Nervosa. Psychiatry Research, 236, 165-172. http://doi.org/10.1016/j.psychres.2015.12.004

Mardaga, S., \& Iakimova, G. (2014). Neurocognitive processing of emotion facial expressions in individuals with self-reported depressive symptoms: The role of personality and anxiety. Neurophysiologie Clinique, 44(5), 447-455. http://doi.org/10.1016/j.neucli.2014.08.007

McIntosh, D. N., Reichmann-Decker, A., Winkielman, P., \& Wilbarger, J. L. (2006). When the social mirror breaks: Deficits in automatic, but not voluntary, mimicry of emotional facial expressions in autism. Developmental Science, 9(3), 295-302. http://doi.org/10.1111/j.14677687.2006.00492.x

Renneberg, B., Heyn, K., Gebhard, R., \& Bachmann, S. (2005). Facial expression of emotions in borderline personality disorder and depression. Journal of Behavior Therapy and Experimental Psychiatry, 36(3), 183-196. http://doi.org/10.1016/j.jbtep.2005.05.002

Rowe, S., Jordan, J., McIntosh, V., Carter, F., Frampton, C., Bulik, C., \& Joyce, P. (2011). Dimensional measures of personality as a predictor of outcome at 5-year follow-up in women with $\bigcirc$ bulimia nervosa. Psychiatry Research, 185(3), 414-420. http://doi.org/10.1016/j.psychres.2010.07.017

Schmidt, K. L., \& Cohn, J. F. (2001). Human facial expressions as adaptations: Evolutionary questions in facial expression research. American Journal of Physical Anthropology, Suppl 33, 3-24. http://doi.org/10.1002/ajpa.20001

Segura-García, C., Chiodo, D., Sinopoli, F., \& De Fazio, P. (2013). Temperamental factors predict long-term modifications of eating disorders after treatment. BMC Psychiatry, 13(1), 288. http://doi.org/10.1186/1471-244X-13-288

Stel, M., Van Den Heuvel, C., \& Smeets, R. C. (2008). Facial feedback mechanisms in autistic spectrum disorders. Journal of Autism and Developmental Disorders, 38, 1250-1258. http://doi.org/10.1007/s10803-007-0505-y

Svaldi, J., Griepenstroh, J., Tuschen-Caffier, B., \& Ehring, T. (2012). Emotion regulation deficits in eating disorders: A marker of eating pathology or general psychopathology? Psychiatry Research, 197(1-2), 103-111. http://doi.org/10.1016/j.psychres.2011.11.009 
Tárrega, S., Fagundo, A. B., Jiménez-Murcia, S., Granero, R., Giner-Bartolomé, C., Forcano, L., ... Fernández-Aranda, F. (2014). Explicit and implicit emotional expression in bulimia nervosa in the acute state and after recovery. PloS One, 9(7), e101639. http://doi.org/10.1371/journal.pone.0101639

Tchanturia, K., Dapelo, M. A. M., Harrison, A., \& Hambrook, D. (2015). Why Study Positive Emotions in the Context of Eating Disorders? Current Psychiatry Reports, 17(1), 537. http://doi.org/10.1007/s11920-014-0537-x

Treasure, J., Corfield, F., \& Cardi, V. (2012). A three-phase model of the social emotional functioning in eating disorders. European Eating Disorders Review, 20(6), 431-438. http://doi.org/10.1002/erv.2181

Trémeau, F., Malaspina, D., Duval, F., Corrêa, H., Hager-Budny, M., Coin-Bariou, L., ... Gorman, J. M. (2005). Facial expressiveness in patients with schizophrenia compared to depressed patients and nonpatient comparison subjects. American Journal of Psychiatry, 162(1), 92-101. http://doi.org/10.1176/appi.ajp.162.1.92

Via, E., Soriano-Mas, C., Sánchez, I., Forcano, L., Harrison, B. J., Davey, C. G., ... Cardoner, N. (2015). Abnormal Social Reward Responses in Anorexia Nervosa: An fMRI Study. PloS One, 10(7), e0133539. http://doi.org/10.1371/journal.pone.0133539

Wallace, L. M., Masson, P. C., Safer, D. L., \& von Ranson, K. M. (2014). Change in emotion regulation during the course of treatment predicts binge abstinence in guided self-help dialectical behavior therapy for binge eating disorder. Journal of Eating Disorders, 2(1), 35. http://doi.org/10.1186/s40337-014-0035-x

Werner, K., \& Gross, J. J. (2010). Emotion regulation and psychopathology: A conceptual framework. In A. M. Kring \& D.M. Sloan (Eds.), Emotion regulation and psychopathology: A transdiagnostic approach to etiology and treatment (pp. 13-37). New York: Guilford Press

Wolz, I., Aguiera, Z., Granero, R., Jiménez-Murcia, S., Gratz, K. L., Menchón, J. M., \& FernándezAranda, F. (2015). Emotion regulation in disordered eating: Psychometric properties of the Difficulties in Emotion Regulation Scale among Spanish adults and its interrelations with personality and clinical severity. Frontiers in Psychology, 6, 907. http://doi.org/10.3389/fpsyg.2015.00907 


\section{Tables}

Table 1. Comparison of BMI, EDI-2, SCL-90-R and TCI-R mean values between groups.

\begin{tabular}{|c|c|c|c|c|c|c|c|c|}
\hline & & $\mathrm{HC}($ & =15) & BSD & $=28)$ & t-tes & & Cohen's \\
\hline & $\alpha$ & Mean & SD & Mean & SD & $\mathrm{T}(d f=41)$ & ${ }^{1} p$ & $|d|$ \\
\hline Body mass index $\left(\mathrm{kg} / \mathrm{m}^{2}\right)$ & & 21.09 & 1.88 & 26.34 & 6.23 & 2.60 & .014 & 1.14 \\
\hline EDI-2: Drive for thinness & .908 & 1.40 & 3.40 & 15.57 & 4.33 & 10.97 & $<.001$ & 3.64 \\
\hline EDI-2: Body dissatisfaction & .934 & 2.73 & 4.08 & 19.96 & 6.25 & 9.61 & $<.001$ & 3.26 \\
\hline EDI-2: Interoceptive awareness & .881 & 0.40 & 0.91 & 12.68 & 5.48 & 8.56 & $<.001$ & 3.12 \\
\hline EDI-2: Bulimia & .885 & 0.13 & 0.52 & 10.18 & 5.42 & 7.13 & $<.001$ & 2.61 \\
\hline EDI-2: Interpersonal distrust & .890 & 0.27 & 0.59 & 5.54 & 5.16 & 3.92 & $<.001$ & 1.43 \\
\hline EDI-2: Ineffectiveness & .928 & 0.67 & 1.54 & 11.82 & 7.34 & 5.78 & $<.001$ & 2.10 \\
\hline EDI-2: Maturity fears & .700 & 3.13 & 3.25 & 6.39 & 4.54 & 2.46 & .037 & 0.83 \\
\hline EDI-2: Perfectionism & .740 & 3.13 & 2.92 & 5.61 & 4.33 & 1.98 & .055 & 0.67 \\
\hline EDI-2: Impulse regulation & .778 & 0.33 & 0.90 & 6.71 & 5.23 & 4.66 & $<.001$ & 1.70 \\
\hline EDI-2: Ascetism & .648 & 1.00 & 1.36 & 8.07 & 3.37 & 7.77 & $<.001$ & 2.75 \\
\hline EDI-2: Social insecurity & .890 & 0.47 & 0.64 & 8.04 & 5.04 & 5.76 & $<.001$ & 2.11 \\
\hline EDI-2: Total score & .976 & 13.67 & 13.52 & 110.82 & 37.11 & 9.75 & $<.001$ & 3.48 \\
\hline SCL-90: Somatization & .956 & 0.40 & 0.35 & 2.02 & 1.09 & 5.56 & $<.001$ & 2.00 \\
\hline SCL-90: Obsessive/compulsive & .922 & 0.46 & 0.38 & 2.06 & 0.86 & 6.81 & $<.001$ & 2.40 \\
\hline SCL-90: Interpersonal sensitivity & .936 & 0.38 & 0.43 & 2.11 & 0.98 & 6.49 & $<.001$ & 2.29 \\
\hline SCL-90: Depressive & .952 & 0.46 & 0.32 & 2.22 & 0.95 & 6.92 & $<.001$ & 2.48 \\
\hline SCL-90: Anxiety & .933 & 0.31 & 0.28 & 1.80 & 0.97 & 5.76 & $<.001$ & 2.08 \\
\hline SCL-90: Hostility & .942 & 0.24 & 0.29 & 1.38 & 1.06 & 4.06 & .003 & 1.47 \\
\hline SCL-90: Phobic anxiety & .878 & 0.07 & 0.16 & 1.06 & 0.98 & 3.84 & .005 & 1.40 \\
\hline SCL-90: Paranoid Ideation & .885 & 0.36 & 0.45 & 1.43 & 0.87 & 4.46 & .001 & 1.55 \\
\hline SCL-90: Psychotic & .908 & 0.14 & 0.20 & 1.25 & 0.78 & 5.37 & $<.001$ & 1.94 \\
\hline SCL-90: GSI score & .989 & 0.32 & 0.22 & 1.83 & 0.82 & 6.93 & $<.001$ & 2.51 \\
\hline SCL-90: PST score & .989 & 22.33 & 15.30 & 64.36 & 17.83 & 7.72 & $<.001$ & 2.53 \\
\hline SCL-90: PSDI score & .989 & 1.21 & 0.38 & 2.42 & 0.57 & 7.45 & $<.001$ & 2.53 \\
\hline TCl-R: Novelty seeking & .820 & 104.13 & 12.05 & 102.32 & 16.01 & 0.38 & .704 & 0.13 \\
\hline TCI-R: Harm avoidance & .933 & 89.80 & 14.84 & 121.00 & 18.35 & 5.66 & $<.001$ & 1.87 \\
\hline TCI-R: Reward dependence & .819 & 111.93 & 8.35 & 101.75 & 14.99 & 2.43 & .045 & 0.84 \\
\hline TCI-R: Persistence & .875 & 117.13 & 14.17 & 109.11 & 19.68 & 1.39 & .279 & 0.47 \\
\hline TCI-R: Self-directedness & .899 & 150.07 & 14.71 & 113.04 & 18.42 & 6.71 & $<.001$ & 2.22 \\
\hline TCI-R: Cooperativeness & .823 & 141.47 & 14.73 & 135.25 & 15.31 & 1.29 & .288 & 0.41 \\
\hline TCI-R: Self-Transcendence & .838 & 21.09 & 1.88 & 26.34 & 6.23 & 0.99 & .370 & 0.31 \\
\hline
\end{tabular}

SD: standard deviation. HC: healthy controls. BSD: bulimic spectrum disorder. ${ }^{l} p$-value includes Bonferroni-Finner's correction. 
GSI: global severity index. PST: positive symptom total. PSDI: positive symptom distress index.

$\alpha$ : Cronbach's alpha in sample. Bold: moderate $(|d|>0.50)$ to high $(|d|>0.80)$ effect size for mean difference.

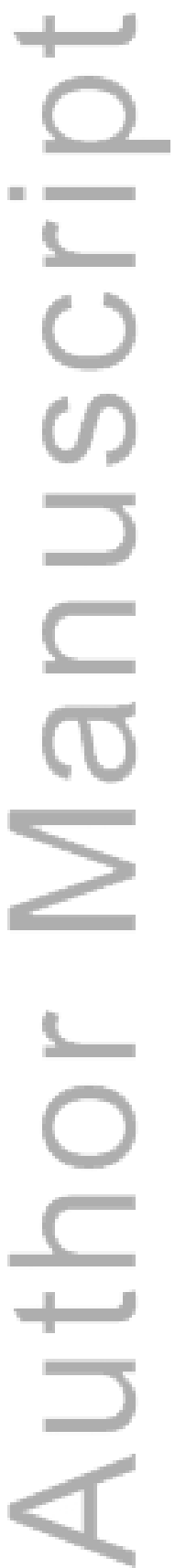

This article is protected by copyright. All rights reserved. 
Table 2. Comparison of facial expression (joy and anger) mean scores between groups.

\begin{tabular}{|l|ccccccc}
\hline & \multicolumn{2}{|c}{$\mathrm{HC}(n=15)$} & \multicolumn{2}{c}{$\mathrm{BSD}(n=28)$} & \multicolumn{2}{c}{ Mean comparison } & \multicolumn{2}{c}{ Cohen's } \\
& Mean & $\mathrm{SD}$ & Mean & $\mathrm{SD}$ & Wald $\left(\chi^{2}\right)$ & ${ }^{1} p$ & $|d|$ \\
\hline Facial joy (seconds) & 975.33 & $(545.91)$ & 880.00 & $(504.38)$ & 94.23 & $<.001$ & 0.18 \\
\hline Facial anger (seconds) & 179.33 & $(302.29)$ & 65.71 & $(166.39)$ & 902.6 & $<.001$ & $\mathbf{0 . 5 0}$ \\
\hline
\end{tabular}

SD: standard deviation. HC: healthy controls. BSD: bulimic spectrum disorder. ${ }^{l} p$-value includes Bonferroni-Finner's correction. Bold: moderate $(|d|>0.50)$ to high $(|d|>0.80)$ effect size for mean difference.

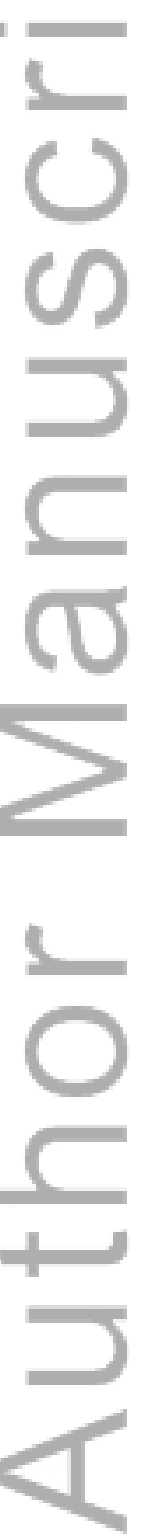


Table 3. Associations between facial emotion expression (joy and anger) and personality traits:

partial correlations adjusted for BMI, ED severity (EDI2-total) and SCL-90-depression.

\begin{tabular}{|lcc}
\hline & Joy & Anger \\
\hline TCl-R: Novelty seeking & .360 & .280 \\
\hline TCl-R: Harm avoidance & -.191 & .069 \\
\hline TCl-R: Reward dependence & .441 & .236 \\
\hline TCl-R: Persistence & -.020 & .109 \\
\hline TCl-R: Self-directedness & .348 & -.473 \\
\hline TCl-R: Cooperativeness & .253 & -.089 \\
\hline TCl-R: Self-Transcendence & .160 & -.166 \\
\hline
\end{tabular}

Bold: good effect size $(|r|>.30)$. Analysis for BSD sample $(n=28)$.

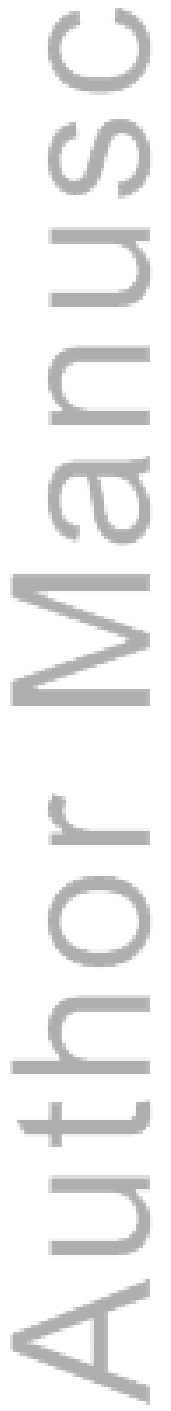

This article is protected by copyright. All rights reserved. 
Personality traits and emotion expression

Table 4. Predictive model of the emotions joy and anger.

\begin{tabular}{|c|c|c|c|c|c|c|c|c|c|c|}
\hline & & $B$ & SE & Beta & t-stat. & $p$ & \multicolumn{2}{|c|}{$95 \% \mathrm{Cl}(\mathrm{B})$} & $\Delta \mathrm{R}^{2}$ & $p$ \\
\hline \multicolumn{11}{|c|}{ Criterion: facial joy. } \\
\hline \multirow[t]{4}{*}{ Block 1} & Constant & 36.23 & 553.68 & & 0.07 & .948 & -1115.22 & 1187.68 & .116 & .451 \\
\hline & Body mass index $\left(\mathrm{kg} / \mathrm{m}^{2}\right)$ & 26.15 & 16.99 & .322 & 1.54 & .139 & -9.18 & 61.49 & & \\
\hline & ED severity: EDI-2 total & 3.22 & 4.17 & .227 & 0.77 & .449 & -5.45 & 11.88 & & \\
\hline & SCL-90-R: depressive & -97.48 & 159.51 & -.181 & -0.61 & .548 & -429.20 & 234.24 & & \\
\hline \multirow[t]{6}{*}{ Block 2} & Constant & -4034.40 & 1396.06 & & -2.89 & .009 & -6956.38 & -1112.41 & .304 & .018 \\
\hline & Body mass index $\left(\mathrm{kg} / \mathrm{m}^{2}\right)$ & 24.61 & 14.65 & .303 & 1.68 & .109 & -6.04 & 55.27 & & \\
\hline & ED severity: EDI-2 total & 11.56 & 4.50 & .814 & 2.57 & .019 & 2.14 & 20.97 & & \\
\hline & SCL-90-R: depressive & -144.99 & 137.05 & -.270 & -1.06 & .303 & -431.83 & 141.85 & & \\
\hline & TCI-R: reward dependence & 16.57 & 6.53 & .492 & 2.54 & .020 & 2.91 & 30.23 & & \\
\hline & TCI-R: self-directedness & 14.34 & 6.89 & .491 & 2.08 & .050 & 0.09 & 28.76 & & \\
\hline \multicolumn{11}{|c|}{ Criterion: facial anger } \\
\hline \multirow[t]{4}{*}{ Block 1} & Constant & 61.99 & 201.45 & & 0.31 & .761 & -356.96 & 480.94 & .012 & .096 \\
\hline & Body mass index $\left(\mathrm{kg} / \mathrm{m}^{2}\right)$ & 0.40 & 6.18 & .014 & 0.06 & .949 & -12.46 & 13.26 & & \\
\hline & ED severity: EDI-2 total & -0.58 & 1.52 & -.118 & -0.38 & .707 & -3.73 & 2.57 & & \\
\hline & SCL-90-R: depressive & 27.19 & 58.04 & .147 & 0.47 & .644 & -93.51 & 147.88 & & \\
\hline \multirow[t]{5}{*}{ Block 2} & Constant & 957.42 & 414.88 & & 2.31 & .032 & 91.98 & 1822.85 & .221 & .026 \\
\hline & Body mass index $\left(\mathrm{kg} / \mathrm{m}^{2}\right)$ & 2.32 & 5.64 & .083 & 0.41 & .685 & -9.44 & 14.08 & & \\
\hline & ED severity: EDI-2 total & -2.64 & 1.62 & -.541 & -1.64 & .118 & -6.01 & 0.73 & & \\
\hline & SCL-90-R: depressive & 27.98 & 52.40 & .151 & 0.53 & .599 & -81.31 & 137.28 & & \\
\hline & TCI-R: self-directedness & -6.36 & 2.65 & -.633 & -2.40 & .026 & -11.89 & -0.84 & & \\
\hline
\end{tabular}

Results obtained in multiple regression for BSD sample $(n=28)$.

ED: eating disorder. $\Delta \mathrm{R}^{2}$ : change in $\mathrm{R}^{2}$ coefficient for the block-step.

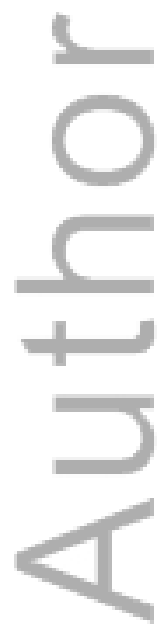


Personality traits and emotion expression

\section{Figure legend}

Figure 1. (A) Joy expression detection (B) Anger expression detection (C) Scene from the video game interface.

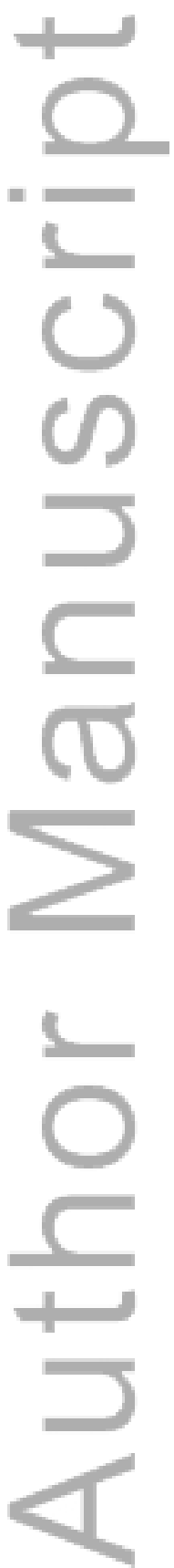

This article is protected by copyright. All rights reserved. 

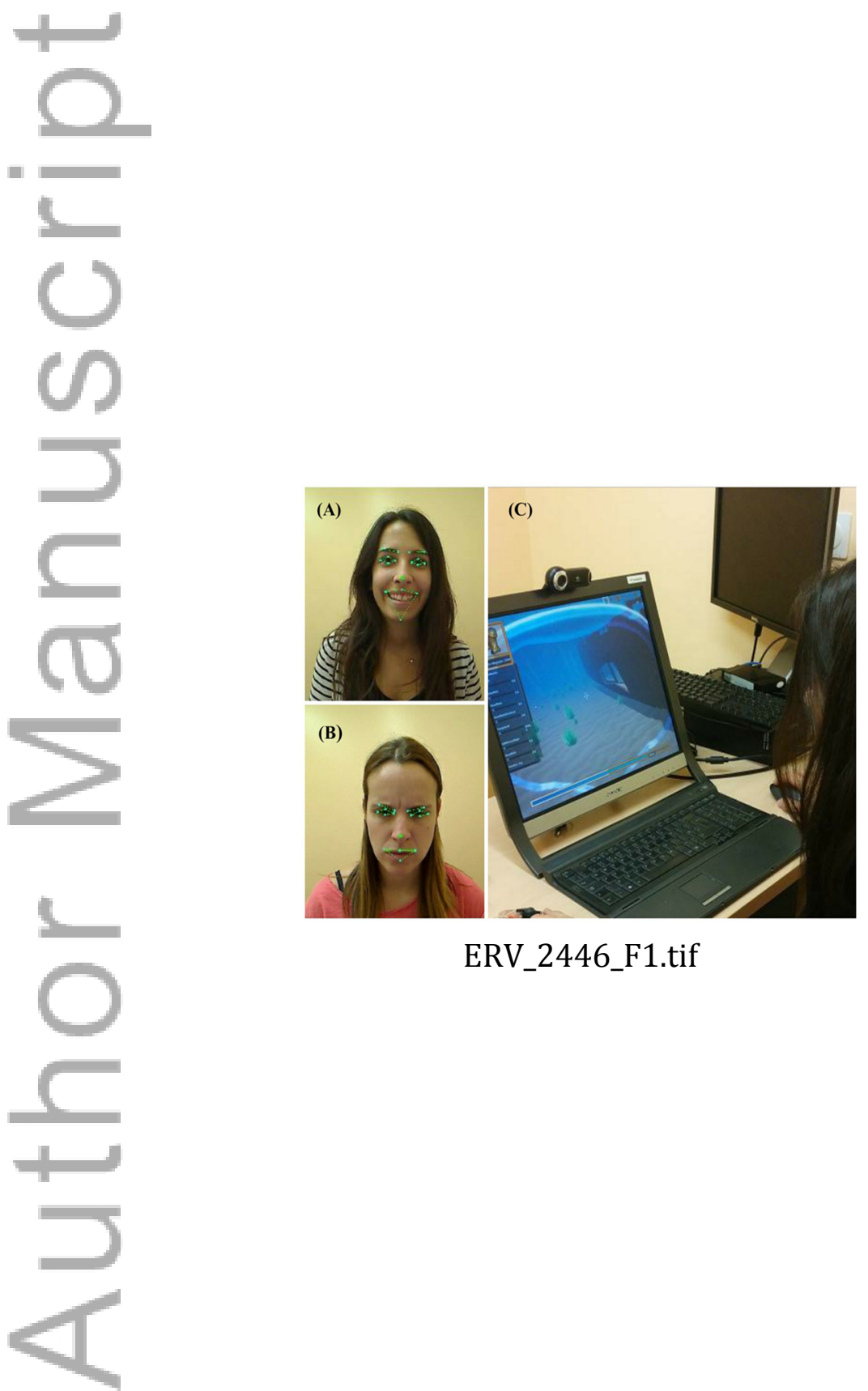

This article is protected by copyright. All rights reserved. 


\section{University Library}

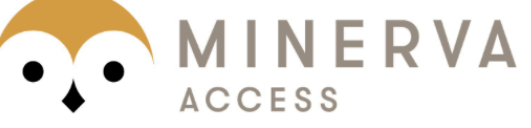

A gateway to Melbourne's research publications

Minerva Access is the Institutional Repository of The University of Melbourne

Author/s:

Giner-Bartolome, C;Steward, T;Wolz, I;Jimenez-Murcia, S;Granero, R;Tarrega, S;Antonio

Fernandez-Formoso, J;Soriano-Mas, C;Menchon, JM;Fernandez-Aranda, F

Title:

The Influence of Personality Traits on Emotion Expression in Bulimic Spectrum Disorders: A Pilot Study

Date:

2016-07-01

Citation:

Giner-Bartolome, C., Steward, T., Wolz, I., Jimenez-Murcia, S., Granero, R., Tarrega, S., Antonio Fernandez-Formoso, J., Soriano-Mas, C., Menchon, J. M. \& Fernandez-Aranda, F. (2016). The Influence of Personality Traits on Emotion Expression in Bulimic Spectrum Disorders: A Pilot Study. EUROPEAN EATING DISORDERS REVIEW, 24 (4), pp.320-328. https://doi.org/10.1002/erv.2446.

Persistent Link:

http://hdl.handle.net/11343/291108 